\title{
Is PRP useful in alveolar cleft reconstruction? Platelet-rich plasma in secondary alveoloplasty
}

\author{
Ramon Luaces-Rey ${ }^{1}$, Jorge Arenaz-Búa ${ }^{1}$, José-Luis López-Cedrún-Cembranos ${ }^{1}$, Susana Herrero-Patiño ${ }^{2}$, \\ Sheyla Sironvalle-Soliva ${ }^{1}$, Emma Iglesias-Candal ${ }^{1}$, María Pombo-Castro ${ }^{1}$
}

\author{
${ }^{1}$ Department of Oral and Maxillofacial Surgery \\ ${ }^{2}$ Orthodontist of the Craniomaxillofacial Malformation Unit \\ A Coruña University Hospital
}

Correspondence:

Servicio de Cirugia Maxilofacial

Complexo Hospitalario A Coruña

As Xubias 84

15006, A Coruña, Spain

ramon.luaces.rey@sergas.es

\author{
Luaces-Rey R, Arenaz-Búa J, López-Cedrún-Cembranos JL, Herrero-Pa- \\ tiño S, Sironvalle-Soliva S, Iglesias-Candal E, Pombo-Castro M. Is PRP \\ useful in alveolar cleft reconstruction? Platelet-rich plasma in secondary \\ alveoloplasty. Med Oral Patol Oral Cir Bucal. 2010 Jul 1;15 (4):e619-23. \\ http://www.medicinaoral.com/medoralfree01/v15i4/medoralv15i4p619.pdf

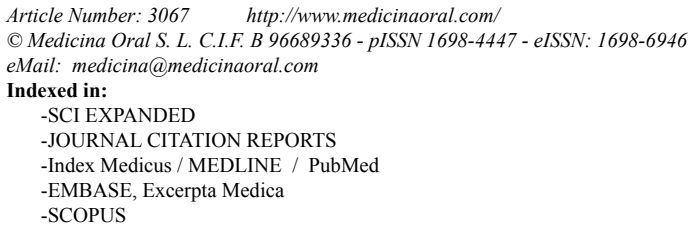

Received: 29/07/2009

Accepted: 28/11/2009

\begin{abstract}
Objective: Cleft lip and palate is a congenital facial malformation with an established treatment protocol. Mixed dentition period is the best moment for correct maxillary bone defect with an alveoloplasty. The aim of this surgical procedure is to facilitate dental eruption, re-establish maxillary arch, close any oro-nasal communication, give support to nasal ala, and in some cases allow dental rehabilitation with osteointegrated implants.

Study design: Twenty cleft patients who underwent secondary alveoloplasty were included. In 10 of them autogenous bone graft were used and in other 10 autogenous bone and platelet-rich plasma (PRP) obtained from autogenous blood. Bone formation was compared by digital orthopantomography made on immediate post-operatory and 3 and 6 months after the surgery.

Results: No significant differences were found between both therapeutic groups on bone regeneration.

Conclusion: We do not find justified the use of PRP for alveoloplasty in cleft patients' treatment protocol.
\end{abstract}

Key words: Cleft lip and palate, platelet-rich plasma, bone regeneration.

\section{Introduction}

Cleft lip and palate is the most prevalent congenital facial malformation. It is present in 1 of 500-1000 liveborn babies, with several severity levels. Treatment sequence is widely accepted and includes alveoloplasty at 7-9 years in order to correct maxillary bone defect. Since Boyne et al. (1) popularized secondary alveoloplasty in cleft patients (1), many studies have been pub- lished about ideal timing, surgical technique, radiological evaluation, orthodontic treatment, bone distraction or rehabilitation with dental implants $(1,2)$.

Alveoloplasty may be performed primary before 2 years. After that moment it is called secondary alveoloplasty. If it is done between 2-5 years (early alveoloplasty), after 12 years (late alveoloplasty) and between 5-12 years it is called intermediate or real secondary al- 
veoloplasty. Even it could be differentiated within real secondary alveoloplasty between early secondary if it is done before central incisor eruption (before 9 years) and late secondary alveoloplasty if is done when canine root is formed between $1 / 4$ and 2/3 (9-11 years). It was already published that timing of the operation is a critical factor. When alveoloplasty is performed before canine eruption, successful rate is higher and is comparable independently of the cleft severity. When alveoloplasty is done late (after canine eruption) successful rate decreases and cleft severity influences in a negative manner on procedure success (3).

The preferable moment for bone graft in alveoloar cleft is in the period of mixed dentition when canine root is formed between $1 / 4$ and $1 / 2$ around $7-9$ years. Reconstruction is done with autologous bone graft and the aim of the procedure is to close oro-nasal communication, permit canine eruption, give bone support to adjacent teeth, facilitate orthodontic treatment, contribute to stability and continuity to maxillary arch (avoiding collapse of structures previously expanded by orthodontics), give support to nasal ala and allow dental rehabilitation with osteointegrated dental implants when necessary (2). By the other hand, platelet-rich plasma (PRP) is defined as high concentration of autologous platelets in a small volume of autologous plasma (4). Platelets contained in this autologous concentrate release their alpha granules during the first minutes of their activation. These contains molecules as PDGF, TGF-B, IGF, VEGF and others that stimulate proliferation, chemiotaxis and differentiation of osteogenesis essential cells accelerating the process. During the last 20 years, PRP has been used in many applications such as accelerate burn healing, chronic ulcers, knee ligament repair, hemostatic or retinal neurogenesis. Many works have show by randomized clinical trials its utility in soft tissues regeneration (5-8). The objective of this study is to evaluate the usefulness of mixing PRP with autologous bone graft in bone regeneration of alveolar cleft compared to autologous bone without PRP.

\section{Patients and Methods}

During the period 1999-2007, 64 alveoloplasties were performed in the Department of Oral and Maxillofacial Surgery in A Coruña University Hospital. 38 of these were secondary alveoloplasties (before canine eruption). Twenty patients who underwent secondary bone graft in the alveolar cleft were included in this study. In the first 10 patients autologous bone graft (iliac bone in most of them) and $1 \mathrm{cc}$ of PRP was used. PRP was obtained from a self donation done the same day of the operation. In the other 10 patients the bone grafting was done without PRP.

In our protocol, radiographic control is done from 5 years old in order to determine the best moment for the surgery. Preoperatory orthodontic treatment is done with the aim of expanding maxillary arch, teeth alignment and make a gap for the bone graft. Orthodontics continues for 8-12 weeks after the alveoloplasty. If the orthodontic arch wire crosses the alveolar cleft, it should be removed just before surgery. In bilateral cleft, the orthodontic arch is placed back after the procedure in the operating room and maintained for 8 weeks in order to contribute to premaxilla and bone graft stability. Cancellous iliac bone was the used graft in most of cases. Root development is evaluated radiographically (periapical radiography or orthopantomography) to determine the appropriate moment for the alveoloplasty. All lip and palate cleft patients were candidates to undergo a secondary alveoloplasty. Naso-tracheal intubation by the non-affected side was used in unilateral clefts and oro-tracheal in bilateral cleft patients. Prophylactic administration of Amoxicillin-clavulanic acid was done half an hour before the surgery and antibiotic is maintained for 8 days after the operation.

Two surgical teams work at the same time, one obtaining the iliac crest graft and the other performing the alveoloplasty itself. No drain is used in any surgical field and all patients were operated by the same surgeon (JLC). This surgeon prepares the surgical field in the alveolar cleft, closes oro-nasal communication if exists, and performs the alveoloplasty itself with the bone obtained by the other surgical team. Boyne and Sands (1) described the procedure of grafting the cancellous iliac bone on the maxillary defect. The day of the operation 1cc of PRP was obtained from $10 \mathrm{cc}$ of whole blood drawn from the patient. The Department of Hematology obtained the PRP by a double centrifuge of the specimen. In the operating room calcium chlorate was added and the product is incubated for 3 minutes at $37^{\circ} \mathrm{C}$ until a bright red clot is obtained. Cancellous bone and PRP are mixed and the malleable material is inserted into the alveolar cleft. Gingival mucoperiosteal flaps should be closed tension-free. Periosteal incisions should be done if necessary. Closure is done with resorbable $4 / 0$ material. Margins of the palatal flaps on the oro-nasal fistula course are refreshed, granulation tissue removed and watertight closure with resorbable 4/0 material is done. Both vestibular flaps are sutured between them along the course of the original fistula and to the palatal flaps on the alveolar ridge over the cleft area. Patients were discharged 24-48 hours after the surgery.

Bone formation on alveolar cleft was registered by digital orthopantomography obtained on immediate postoperatory, at 3 and 6 months after the surgery. Bone increase was measured in a subjective but blind manner, by a gradual 1-4 scale (1 minimum bone formation, 4 maximum bone formation) scored by four blind observers, all of them experts surgeons from the Department of Oral and Maxillofacial Surgery. Previous calibration 
process was needed between all the observers, in order to assess the agreement grade. Computerized tomography (CT) and biopsy were rejected because of economic and ethical reasons.

\section{Results}

Orthopantomography mean score was obtained from each of the 20 patients in the immediate post-operatory and 3 and 6 months after the surgery. Bone increase between third and sixth month was calculated. The first group (PRP group) consisted on 6 men and 4 women with a mean age of 8.7 years. They were 7 unilateral and 3 bilateral clefts. In 1 case was employed tibial bone graft, in 2 cases the donor area was mandibular symphysis and iliac crest in the other 7 cases.

The second group (non-PRP group) was composed by 7 men and 3 women with an average age of 9.1 years. Seven patients were unilateral cleft and three were bilateral. Iliac bone graft was used in all of them. Mean score of bone formation in each patient in the immediate post-operatory and 3 and 6 months after the surgery is recorded in table 1 . Bone increase between third and sixth month is observed too.

Statistical analysis was done with the Mann-Witney test and p-value of less than 0.05 was considered statistically significant. No statistically significant differences in bone formation were found between both groups in early post-operatory (with PRP 1,32+-0,38 and without PRP 1,89+-0,76), neither after 3 months (with PRP 2,2+-0,7 and without PRP 2,64+-0,76) or after 6 months (with PRP 2,43+-0,6 and without PRP 3,17+-0,866). No statistically significant differences in bone increase in the period 0-3 months (with PRP 0,88+-0,77 and without PRP 0,75+-1,1) or the period 3-6 months (with PRP 0,23+-0,5 and without PRP $0,53+-0,64)$, or in $0-6$ months (with PRP 1,1+-0,8 and without PRP 1,2+-1,1) were found too.

\section{Discussion}

PRP use in oral surgery was initially based on wound healing acceleration due to growth factor release from activated platelet (6). Eighty eight autologous grafts in human mandibles were done in one of most important initial studies. In half of them PRP was added, and

Table 1. Patients classification by age, sex, uni or bilateral cleft, kind of bone graft used, PRP addition or not, and their score on bone formation scale in immediate post-operatory, at 3 months, at 6 moths, and the increase between 3-6 months.

\begin{tabular}{|c|c|c|c|c|c|c|c|c|c|}
\hline PATIENT & Sex & Age & $\begin{array}{c}\text { imme- } \\
\text { diate }\end{array}$ & 3 months & 6 months & 3-6 months & $\begin{array}{l}\text { Uni- } \\
\text { bilat }\end{array}$ & bone & PRP \\
\hline 1 & $\mathrm{M}$ & $7 \mathrm{y} 2 \mathrm{~m}$ & 1 & 2 & 3,3 & 1,3 & $\mathrm{U}$ & iliac & YES \\
\hline 2 & $\mathrm{~F}$ & $7 y 8 m$ & 1 & 3 & 3,3 & 1,3 & $\mathrm{U}$ & iliac & YES \\
\hline 3 & $\mathrm{~F}$ & $9 y 6 m$ & 1,3 & 1,7 & 1,7 & 0 & $\mathrm{U}$ & iliac & YES \\
\hline 4 & $\mathrm{M}$ & $8 \mathrm{yl0m}$ & 1,3 & 1,7 & 2 & 0,3 & $\mathrm{U}$ & iliac & YES \\
\hline 5 & $\mathrm{M}$ & $8 \mathrm{y} 9 \mathrm{~m}$ & 1,3 & 1,7 & 1,7 & 0 & $\mathrm{U}$ & tibial & YES \\
\hline 6 & $\mathrm{~F}$ & $7 \mathrm{y} 11 \mathrm{~m}$ & 2 & 2,3 & 2,3 & 0 & $\mathrm{~B}$ & symphysis & YES \\
\hline 7 & $\mathrm{M}$ & $7 \mathrm{y} 10 \mathrm{~m}$ & 1,3 & 3,7 & 3 & $-0,7$ & B & symphysis & YES \\
\hline 8 & $\mathrm{~F}$ & $9 y$ & 1 & 1,3 & 2 & 0,7 & $\mathrm{U}$ & iliac & YES \\
\hline 9 & $\mathrm{M}$ & $8 \mathrm{y} 9 \mathrm{~m}$ & 2 & 2,3 & 2,3 & 0 & $\mathrm{U}$ & iliac & YES \\
\hline 10 & $\mathrm{M}$ & $10 \mathrm{y} 7 \mathrm{~m}$ & 1 & 2,3 & 2,7 & 0,3 & $\mathrm{~B}$ & iliac & YES \\
\hline 11 & $\mathrm{M}$ & $6 y 11 \mathrm{~m}$ & 3,3 & 2,7 & 3,3 & 0,6 & $\mathrm{U}$ & iliac & $\mathrm{NO}$ \\
\hline 12 & $\mathrm{~F}$ & $9 \mathrm{y} 3 \mathrm{~m}$ & 2,7 & 1,3 & 1,7 & 0,3 & $\mathrm{U}$ & iliac & $\mathrm{NO}$ \\
\hline 13 & $\mathrm{~F}$ & $10 \mathrm{y} 2 \mathrm{~m}$ & 1,7 & 3,7 & 3 & $-0,7$ & $\mathrm{U}$ & iliac & $\mathrm{NO}$ \\
\hline 14 & $\mathrm{M}$ & $8 \mathrm{y} 3 \mathrm{~m}$ & 1,3 & 2 & 3,3 & 1,3 & $\mathrm{U}$ & iliac & $\mathrm{NO}$ \\
\hline 15 & $\mathrm{M}$ & $8 y$ & 1,3 & 2 & 1,7 & $-0,3$ & $\mathrm{~B}$ & iliac & $\mathrm{NO}$ \\
\hline 16 & $\mathrm{M}$ & $8 \mathrm{y} 7 \mathrm{~m}$ & 2 & 2,3 & 3 & 1 & $\mathrm{~B}$ & iliac & $\mathrm{NO}$ \\
\hline 17 & $\mathrm{M}$ & $11 \mathrm{y} 6 \mathrm{~m}$ & 1 & 2,7 & 4 & 1,3 & $\mathrm{U}$ & iliac & $\mathrm{NO}$ \\
\hline 18 & $\mathrm{~F}$ & $7 \mathrm{y} 2 \mathrm{~m}$ & 2,3 & 3 & 3,7 & 0,7 & $\mathrm{U}$ & iliac & $\mathrm{NO}$ \\
\hline 19 & $\mathrm{M}$ & $8 y 11 \mathrm{~m}$ & 1 & 3 & 4 & 1 & B & iliac & $\mathrm{NO}$ \\
\hline 20 & $\mathrm{~F}$ & $12 \mathrm{y} 10 \mathrm{~m}$ & 2,3 & 3,7 & 4 & 0,33 & $\mathrm{U}$ & iliac & $\mathrm{NO}$ \\
\hline TOTAL & & & 33,1 & 48,4 & 56 & 7,4 & & & \\
\hline MEAN & & 8,8 years & 1,655 & 2,42 & 2,8 & 0,37 & & & \\
\hline
\end{tabular}

M: male; F: female; m: months; U: unilateral; B: bilateral. 
higher bone maturity and density than in control group was showed radiographically and histomorphometrically $(7,9)$. Many works have supported the use of PRP in oral surgery, being accepted its utility in periodontal and soft tissue regeneration $(4,6-8)$. But other authors argue the lack of scientific evidence for defending the use of PRP in bone regeneration and recommend the surgeon to maintain a critical mind (10-13). In one of the most important reported metaanalysis the absence of reliable evidence of any active agent such as bonepromoter molecules or PRP in dental implants treatment is remarked (11). Beneficial effects of PRP in periodontal defects have been probed recently. But efficacy evidence in sinus lift remains weak and these authors can not conclude any other PRP application in odontology based on their reviewed literature (12).

Boyne and Sands (1) started particulated cancellous bone grafting on alveolar clefts during mixed dentition combined with orthodontic treatment in order to contribute to maxillary stability, allow dental eruption thought the grafted bone and facilitate posterior orthodontic treatment. Most of the authors agree that secondary bone grafting during mixed dentition period does not affect significantly to facial growth, because at the 8th year of life most of the maxillary development has already happened. Surgical indication was done in accordance with the orthodontist, based on growth, orthodontic and prosthodontic criteria. An only surgeon (JLC) operated all patients following the same surgical technique. Iliac crest is the preferred donor site in this kind of patients. Other donor sites as tibia or chin are only chosen on small size defects, because of the limited amount of available bone, on an attempt of avoiding temporal sequela after harvesting iliac crest grafts. All mucoperiosteal flaps were designed to cover the bone graft with attached gum. Some authors recommend PRP use in the alveoloplasties because it facilitates bone regeneration (2) and soft tissue healing (5). Other works do not find any long term advantage in use PRP mixed with autologous bone (11).

Secondary alveoloplasty efficacy was supported by authors as Matsui et al. (14) who found that most of cleft patients in his serie had spontaneous canine eruption after real secondary alveoloplasty. Just very few of them needed orthodontic traction. He found relation between width bone defect on nasal side and canine surgical exposure requirement. The way of checking the bone increase remains controversial. Van der Meij et al. (15) proved by CT the remaining grafted bone 1 year after the surgery. His work does not find significant differences between late and early secondary alveoloplasty. But a lesser degree of bone persistence on bilateral cleft (45\%) than in unilateral cleft (70\%) was showed. In spite of that, bone amount was enough for canine eruption. Performing secondary alveoloplasty, Trindade et al. (16) gets $95 \%$ success rate in unilateral clefts and defends periapical radiography to confirm the success of the grafted bone. However Feichtinger et al. (17) making CT $3 \mathrm{D}$ preoperatively and 1, 2 and 3 years postoperatively, describes a bone loss of $49.5 \%$ on the bucco-palatal dimension of the bone transplant during the first year, and remaining constant the following 2 years. He rejects conventional two-dimension radiographs to quantify bone loss. He supports a higher success rate when the gap is closed orthodontically in a short period of time. Oyama et al. (2) compares tertiary alveoloplasty in 7 cleft patients using iliac crest with PRP and another 7 without PRP. He uses CT 3D before and 6 months after the surgery and proves than PRP group formed more bone. He agrees that there is no widely accepted method for bone grafting quantification and suggests that bone formation quantity and quality should be tested. We ruled out bone biopsy and CT before and after the surgery because of the radiation exposure in growing period patients. Lee et al. (18) compares 2 alveoloplasty groups of 35 patients each one with and without PRP. He came to conclusion that PRP is not enough to avoid alveolar graft resorption in secondary alveoloplasty. He applies specific software to evaluate bone formation through sample dental radiographies. We tried to measure bone increase using a computer programme in conjunction with the Radiology Department. An adjacent tooth was used as a correction factor that remains constant in its radiopacity in order to compare formed bone. But the complexity of the anatomical area, erupting teeth and orthodontic appliances prevented to obtain predictable results, so the study was abandoned. Cone Beam Computed Tomography (CBCT) is gaining ground in odontology and maxillofacial surgery (19). Its high imaging quality and anatomical precision in premaxilla (20) would be very useful in a work like this to evaluate bone density. But nowadays economic cost is its great handicap. This study was carried out in a public hospital, and it is impossible to achieve this kind of diagnostic imaging there.

\section{Conclusions}

Alveoloplasty constitutes an excellent surgical method for correcting alveolar cleft. It allows closing oro-nasal fistula, preserving dental health, and performing a correct orthodontic treatment. We consider acceptable our results, agree with reviewed literature. Wide base mucoperiosteal gingival flaps have excellent vascularization and allow a tension-free closure on the grafted alveolus. Our design modification let raise an easy flap with optimal mobility. It does not produce papillar or vestibular sulcus modifications and allows healthy periodontal gum for teeth eruption and successful orthodontic treatment. We do not find evidence for PRP application to facilitate bone formation in secondary alveoloplasty 
of cleft patients, although its consistency makes easier handling and packing the graft. Our serie is too small to obtain conclusive results. More prospective randomized controlled studies are needed to achieve definitive data against or in favour of PRP use on alveoloplasty of cleft patients. There are still two important points with no agreement. The first one is to establish a standard method of obtaining PRP so that its properties were comparable in different studies. The second point is to accord an accepted way to quantify bone increase after the alveoloplasty.

\section{References}

1. Boyne PJ, Sands NR. Secondary bone grafting of residual alveolar and palatal clefts. J Oral Surg. 1972;30:87-92.

2. Oyama T, Nishimoto S, Tsugawa T, Shimizu F. Efficacy of platelet-rich plasma in alveolar bone grafting. J Oral Maxillofac Surg. 2004;62:555-8

3. Jia YL, Fu MK, Ma L. Long-term outcome of secondary alveolar bone grafting in patients with various types of cleft. Br J Oral Maxillofac Surg. 2006;44:308-12.

4. Marx RE. Platelet-rich plasma: evidence to support its use. J Oral Maxillofac Surg. 2004;62:489-96.

5. Méndez R, López-Cedrún JL, Patiño B, Vázquez I, Martín-Sastre $\mathrm{R}$, Tellado MG, et al. [Platelet-rich plasma (platelet gel) in secondary alveoloplasty in cleft patients]. Cir Pediatr. 2006;19:23-6.

6. Whitman DH, Berry RL, Green DM. Platelet gel: an autologous alternative to fibrin glue with applications in oral and maxillofacial surgery. J Oral Maxillofac Surg. 1997;55:1294-9.

7. Marx RE, Carlson ER, Eichstaedt RM, Schimmele SR, Strauss JE, Georgeff KR. Platelet-rich plasma: Growth factor enhancement for bone grafts. Oral Surg Oral Med Oral Pathol Oral Radiol Endod. 1998;85:638-46.

8. Sammartino G, Tia M, Marenzi G, di Lauro AE, D'Agostino E, Claudio PP. Use of autologous platelet-rich plasma (PRP) in periodontal defect treatment after extraction of impacted mandibular third molars. J Oral Maxillofac Surg. 2005;63:766-70.

9. López-López J, Chimenos-Küstner E, Manzanares-Cespedes C, Muñoz-Sánchez J, Castañeda-Vega P, Jané-Salas E, et al. Histomorphological study of the bone regeneration capacity of platelet-rich plasma, bone marrow and tricalcium phosphate: Experimental study on pigs. Med Oral Patol Oral Cir Bucal. 2009;14:e620-7.

10. Freymiller EG, Aghaloo TL. Platelet-rich plasma: ready or not? J Oral Maxillofac Surg. 2004;62:484-8.

11. Esposito M, Grusovin MG, Coulthard P, Worthington HV. The efficacy of various bone augmentation procedures for dental implants: a Cochrane systematic review of randomized controlled clinical trials. Int J Oral Maxillofac Implants. 2006;21:696-710.

12. Plachokova AS, Nikolidakis D, Mulder J, Jansen JA, Creugers $\mathrm{NH}$. Effect of platelet-rich plasma on bone regeneration in dentistry: a systematic review. Clin Oral Implants Res. 2008;19:539-45.

13. Thor A, Franke-Stenport V, Johansson CB, Rasmusson L. Early bone formation in human bone grafts treated with platelet-rich plasma: preliminary histomorphometric results. Int J Oral Maxillofac Surg. 2007;36:1164-71.

14. Matsui K, Echigo S, Kimizuka S, Takahashi M, Chiba M. Clinical study on eruption of permanent canines after secondary alveolar bone grafting. Cleft Palate Craniofac J. 2005;42:309-13.

15. Van der Meij AJ, Baart JA, Prahl-Andersen B, Valk J, Kostense PJ, Tuinzing DB. Bone volume after secondary bone grafting in unilateral and bilateral clefts determined by computed tomography scans. Oral Surg Oral Med Oral Pathol Oral Radiol Endod. 2001;92:136-41.

16. Trindade IK, Mazzottini R, Silva Filho OG, Trindade IE, Deboni MC. Long-term radiographic assessment of secondary alveolar bone grafting outcomes in patients with alveolar clefts. Oral Surg Oral Med Oral Pathol Oral Radiol Endod. 2005;100:271-7.

17. Feichtinger M, Mossböck R, Kärcher H. Assessment of bone resorption after secondary alveolar bone grafting using three-dimensional computed tomography: a three-year study. Cleft Palate Craniofac J. 2007;44:142-8.

18. Lee C, Nishihara K, Okawachi T, Iwashita Y, Majima HJ, Nakamura N. Aquantitative radiological assessment of outcomes of autogenous bone graft combined with platelet-rich plasma in the alveolar cleft. Int J Oral Maxillofac Surg. 2009;38:117-25.

19. Howerton WB Jr, Mora MA. Advancements in digital imaging: what is new and on the horizon? J Am Dent Assoc. 2008;139 Suppl:20S-24S.

20. Angelopoulos C. Cone beam tomographic imaging anatomy of the maxillofacial region. Dent Clin North Am. 2008;52:731-52.

\section{Acknowledgments}

The authors thank to Ms. Marisa Díaz Salmerón (FirstAssist, Purley, United Kingdom) for help in reviewing the manuscript for English syntax. 